\title{
Períodos protoceltibérico y celtibérico en la necrópolis de Carratiermes (Montejo de Tiermes, Soria). Avance de los resultados obtenidos en la campaña de 1989
}

\author{
José LUIS ARgente Oliver * \\ ADElia Díaz Díaz * \\ Alberto Bescós Corral **
}

Las últimas campañas efectuadas en el Yacimiento de Tiermes se centran en la excavación de la necrópolis celtibérica ubicada en el lugar denominado "Carratiermes" (figs. 1 y 2), a unos 900 metros al nordeste de la ermita románica de Nuestra Señora de Tiermes. La superficie que ocupa este cementerio es bastante amplia, aproximadamente unos 35.000 metros cuadrados, aunque se ha podido comprobar la existencia de espacios vacios de enterramientos entre las áreas fértiles ${ }^{1}$.

* Director del Museo Numantino y de las Excavaciones Arqueológicas en Carratiermes.

"* Coodirectores de las Excavaciones Arqueológicas en la necrópolis Carratiermes.

' Argente Oliver, J.L. y Diaz Diaz Adelia, "La necrópolis celtibérica de Tiermes (Carratiermes, Soria)" NAH., 7 (1979); págs. 95-151; ARGENTE OLIVER, J.L., "Tiermes. Catorce años de excavaciones", Diez años de Arqueologia Soriana (1978-1988). Soria 1989, págs. 76-86; Ruiz Zapatero, G. Y Nunez Garcia, C., "Un presunto ajuar celtibérico procedente de Carratiermes (Soria)". Nvmantia I (1981), págs. 189-194. En posteriores campañas hemos exhumado una serie de conjuntos, de estructuras y de datos de información que permiten valorar Carratiermes desde otro punto de vista, facilitando mucho mejor la comprensión de ciertos aspectos. En este sentido, debemos citar los trabajos que se han lievado a cabo últimamente, dando a conocer diversas parcelas de la necrópolis: ARgente Oliver, J.L. y Diaz DiAz, Adelia, "La necrópolis de Carratiermes (Tiermes, Soria)", comunicación presentada al "Simposio sobre Celtiberos, Daroca, abril de 1988 (en prensa); Argente Oliver, J.L., Bergamin, J., Mateos, 
Los resultados conocidos hasta el presente son importantes, ya que la información que poseemos corresponde a los restos materiales de una etapa cultural de la que sólo se disponia de unas parcas menciones en los textos clásicos, referidos solamente a su etapa final. Los ajuares inventariados hasta el presente han permitido retrotraer la datación de Tiermes hasta mediados-finales del siglo vi a.C., e incluso se han registrado otros materiales que señalan momentos anteriores, aunque su relación es cuantitativamente menor y se hailaron dispersos entre las estructuras funerarias localizadas ${ }^{2}$.

Las intervenciones realizadas en Carratiermes se iniciaron en la primavera de 1977, llevando a cabo diversos sondeos en el área en la que, durante años anteriores, se habian recuperado objetos metálicos al realizar tareas agricolas en las diferentes parcelas por las que se extiende la necrópolis; en los años 1975 y 1976, se entregaron en el Museo Numantino algunos objetos procedentes de este área. Los resultados de 1977 fueron desalentadores, pues tan sólo escasos restos materiales pudieron inventariarse, además de hallarlos fuera de contexto ${ }^{3}$; sin embargo, permitieron confirmar arqueológicamente la presencia de la etapa celtibérica en Tiermes.

\footnotetext{
M.T., Mingarro, F. y López Azcona, C., "Prospección geofisica aplicada a la investigación de la necrópolis de Carratiermes (Montejo de Tiermes, Soria). Primeros resultados", comunicación presentada a las III Jornadas de Teledetecçao e Geofisica aplicada a Arqueologia. Aveiro, septiembre de 1989 (en prensa); Argente Oliver, J.L., Diaz Diaz, A. y Bescós Corral, A., "Caracteristicas de los ajuares funerarios de los periodos protoceltibérico y celtibérico pleno de la necrópolis de Carratiermes, en base a los resultados de la campaña de 1989", Celtiberia (en prensa); IDEM, "La necrópolis celtibérica de Carratiermes", comunicación presentada al "I Simposium de Arqueologia Soriana (en prensa); IDEM, «Placas decoradas celtibéricas en Carratiermes", comunicación presentada al /I Simposium de Arqueologia Soriana (en prensa); Alonso LuBIAS, A., "Broches de cinturón de tipo céltico en la necrópolis celtibérica de Carratiermes", comunicación presentada al // Simposium de Arqueologia Soriana (en prensa); MARtinez Martinez, C., "El armamento de la necrópolis celtibérica de Carratiermes", comunicación presentada al // Simposium de Arqueología Soriana (en prensa); SAIZ RIOS, P., "Representaciones plásticas de la cabeza humana en la necrópolis celtibérica de Carratiermes", comunicación presentada al // Simposium de Arqueologia Soriana (en prensa); Misiego TEJADA, J. y Altares LUCENDO, J., "La cerámica con decoración a peine de la necrópolis de Carratiermes", Comunicación presentada al /l Simposium de Arqueologia Soriana (en prensa); MARTinEZ, A. y HERNANDEZ UAIZAR, E., "Material de época romana en las excavaciones de la necrópolis celtibérica de Carratiermes", comunicación presentada al II Simposium de Arqueologia Soriana (en prensa); Bescos CorRaL, A y ALDECOA RuIz, A., "Bases de datos relacionales para la gestión de excavación: la experiencia de la necrópolis de Carratiermes", comunicación presentada al "I Simposium de Arqueologia Soriana (en prensa).

2 Bescos Corral, A., "Materiales de la Edad del Bronce en la necrópolis celtibérica de Carratiermes (Montejo de Tiermes, Soria)", comunicación presentada al "Simposium de Arqueologia Soriana (en prensa).

3 Argente Oliver, y Diaz Diaz, "La necrópolis", obra citada, 1979, págs. 95-151.
} 


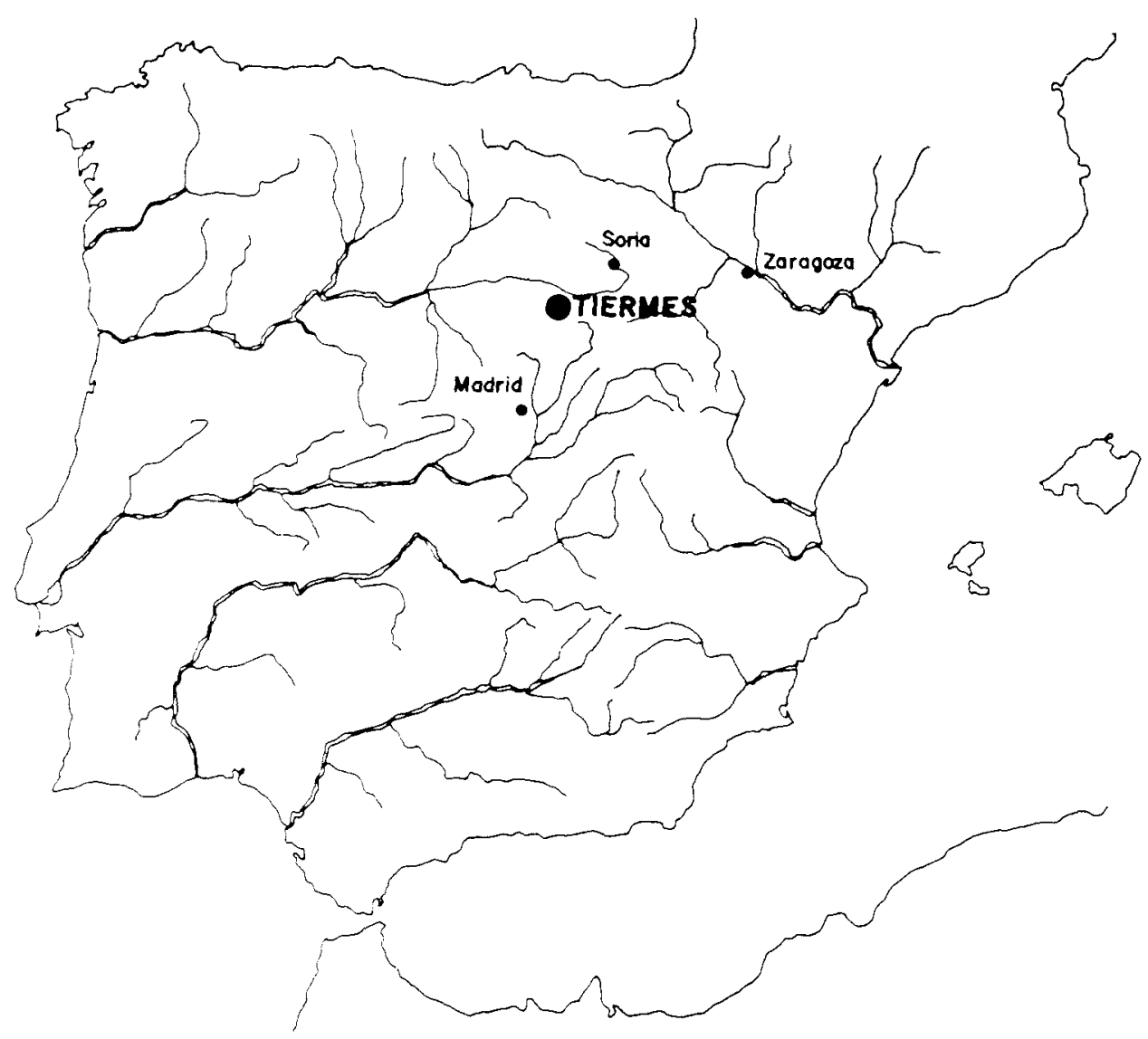

Fig. 1. Situación de Tiermes en la Peninsula lbérica.

Posteriormente, en la primavera de 1986 y en las campañas de 1987,1988 y 1989 se han continuado los trabajos. Los testimonios que tenemos hasta el presente son satisfactorios, y ello permite albergar esperanzas bien fundadas para conocer la importancia de Tiermes en su etapa prerromana, destacándose además como uno de los lugares preponderantes y significativos de la Celtiberia ${ }^{4}$. El número de ajuares, la composición de los mismos, su tipología y las estructuras halladas permiten pensar que, cuando finalicen los trabajos de campo, los resultados

4 Aguilera y Gamboa, E. de (Marqués de Cerralbo), Las necropolis ibericas, Madrid 1916, figs. 36. 37, 39 y 40 y lám. XI; IDEM., Historia Patria, por mis excavaciones arqueológicas, obra inédita vols. III y IV; CABré AGUilo, J., Catálogo Monumental de la Provincia de Soria, Madrid 1917, tomo Ill, obra inédita 

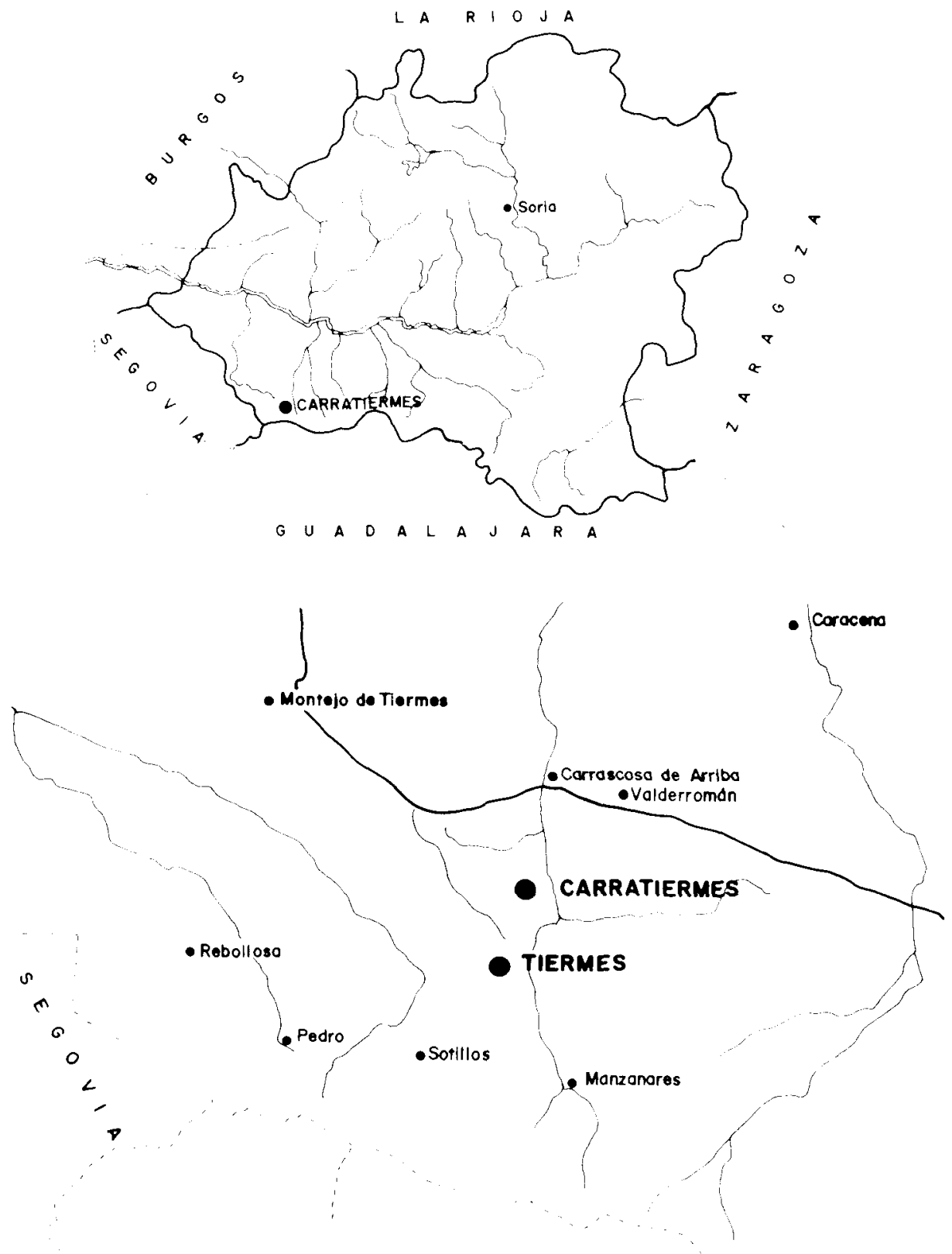

G U A D A L A J A R A

Fig. 2. Situación de Carratiermes dentro de los límites de la Provincia de Soria y de la comarca natural en la que se enclava. 
ayudarán a comprender mejor todo el conjunto de necrópolis que, a ambos lados de la actual división administrativa de las provincias de Soria y Guadalajara, conforman el núcleo de la Celtiberia estricta.

La campaña de 1989 (Semana Santa y Verano) se desarrolló en un área próxima a las de años anteriores, con el fin de completar zonas, pues los trabajos en la necrópolis se iniciaron en distintos puntos, cuyo objetivo era el de conocer la extensión del cementerio. El resultado en 1989 ha sido altamente positivo, ya que se han podido concretar aspectos de las sucesivas fases cronológicas que se distinguen, de estructuras funerarias, de diferencias notables en los ajuares y también se ha reconocido la presencia de mobiliarios pertenecientes a individuos de la sociedad civil y del estamento militar, lo que, en principio, consideramos una importante novedad, pues hasta ahora se sostenia que los ajuares de las necrópolis celtibéricas correspondían al estamento guerrero dirigente. Además de lo expuesto, que incumbe casi exclusivamente a la etapa protoceltibérica, se ha ampliado el área del período plenamente celtibérico; de ambos momentos disponíamos ya de importantes datos, que en la presente campaña se han incrementado y mostrado otras singularidades.

\section{CONOCIMIENTO ACTUAL DE LA NECRÓPOLIS DE CARRATIERMES CON LA INFORMACIÓN QUE SE DISPONE}

Desde que efectuamos la campaña de 1988, y a la vista de los resultados, pudimos establecer, como hipótesis de trabajo, el desarrollo de esta necrópolis desde mediados-fines del siglo vi a. C. hasta mediados-fines del siglo I d. C.; ambos limites cronológicos se mantienen una vez finalizados los trabajos de 1989, confirmándose el más antiguo, pues la tarea desarrollada en la última campaña se ha centrado en las etapas protoceltibérica y celtibérica, dejando la fase final del área cementerial para campañas venideras.

Hay que señalar también que, en 1989 , se ha completado una zona en la que se habia actuado de manera puntual en años anteriores a base de sondeos dispersos, cuando tratábamos de conocer el estado de conservación de la necrópolis y la amplitud de la misma. Así, pues, la cam- 
paña de 1989 se centró paralela a la vía que une el Camino Real y la ciudad de Tiermes, en un área de 896 metros cuadrados; el número total de tumbas fue de 144 , desde la 304 a la 434 , a las que hay que sumar 14 con número anterior, procedentes de estructuras que hoy no las consideramos como tales, registradas en campañas anteriores; también debemos añadir las 39 exhumadas en Semana Santa, lo que hace un total para la campaña de 1989 de 183 tumbas excavadas. El registro total de piezas ha sido de 11.957 , de las que 2.300 corresponden al inventario de Semana Santa. La parte más interna de la zona y alejada del camino pertenece a estructuras funerarias más antiguas (siglos $\vee \mathrm{y}$ y $\vee$ a.C.) mientras que en su exterior registraron tumbas más modernas (siglos IV y III a.C.). Desconocemos todavía si la expansión de la necrópolis se efectuó en círculos o en zonas independientes en torno a la más antigua; ello podrá determinarse cuando la zona del cementerio celtibérico se halle más excavada.

\section{ESTRUCTURAS Y AJUARES DEL PERIODO PROTOCELTIBÉRICO}

El conjunto de tumbas halladas en la campaña de 1989, y correspondientes al periodo de inicio de la necrópolis (siglos VI-V a.C.), manifiestan unas caracteristicas estructurales bien definidas, así como la tipologia de los ajuares depositados en su iriterior.

Por regla general, el mobiliario, principalmente de armas y con algún objeto de adorno realizado en bronce, se colocaba en un rebaje u hoyo de escasa o mediana profundidad, practicado en el conglomerado natural; en ocasiones queda cubierto por una estela informe de piedra, rodeada o nó de una estructura pétrea, mientras que en otras sólo aparece esta última. La diferencia más notoria de lo exhumado durante los periodos de escavación en 1989, reside en que otros enterramientos se hallaron mucho más profundos y contenian un ajuar fundamentalmente de piezas de bronce.

Dentro de los ajuares del período protoceltibérico, es necesario hacer hincapié en la existencia de dos diferentes tipos, que si bien fueron anotados en otras excavaciones ${ }^{5}$, no indicaron la relacion porcentual entre

\footnotetext{
citada.

5 Aguilera y Gamboa, Las necrópolis..., obra citada, 1916; IDEM., Historia Patria..., obra
} 
unos y otros, dándoles además diferente significado al que ahora les atribuimos; no obstante, las observaciones que señalamos quedarán pendientes de ulteriores análisis, como es el caso de los restos óseos, que indicarán la adscripción a uno u otro sexo, y precisarán ser corroborados por posteriores excavaciones en otras necrópolis de la zona.

Los ajuares detectados presentan una clara diferenciación en cuanto a la tipologia de las piezas que los componen; de esta forma, distinguimos entre mobiliario de bronce (correspondiente a individuo civil) y de armas (identificándolo a guerrero):

- Ajuares de bronce. En el conjunto de enterramientos destacan los mobiliarios constituidos por elementos de bronce, sistemáticamente adjudicados hasta hace poco tiempo a tumbas femeninas; sin embargo, hoy esta idea se encuentra en revisión y, sobre la base de los hallazgos de Carratiermes, estamos en condiciones de manifestar que la combinación de determinados elementos de ajuar corresponden a enterramientos masculinos - to que no excluiría necesariamente la atribución de tumbas, difícilmente detectable por otro lado, al sexo femenino, y en cuyo mobiliario se combinan otro tipo de piezas-. Por lo tanto, en espera de corroborar estas conclusiones con los análisis óseos, pensamos que no puede aplicarse ese criterio de diferenciación sexual y, por el contrario, lo que detectamos es un elemento determinante de la posición social del individuo.

Dentro de los conjuntos cerrados con piezas de bronce (en los que suelen figurar siempre una pieza en hierro, como es el caso de pequeños cuchillos de hoja curva), destacan unos objetos que hemos denominado "pectorales"; hasta el presente solamente se conocian algunos ejemplares aislados y/o piezas sueltas de los mismos, pero suponemos que pudieron ser relativamente frecuentes en el mundo celtibérico, dependiendo siempre de la importancia social que el individuo alcanzó en su momento. Hasta ahora, solamente Encarnación Cabré y Juan Antonio Morán los habian definido con esta función, aunque no establecieron ninguna diferenciación tipológica, y tampoco concretaron la constitución de los mismos ${ }^{6}$. En ellos se pueden distinguir diversos modelos, basándonos principalmente en los hallazgos que se han producido en la necrópolis de Carratiermes y en algunos otros ejemplos procedentes de excavaciones

${ }^{6}$ Cabre de moran. E. y Moran Cabré. J. A., "Dos tumbas datables de la necrópolis de Alpanseque (Soria)", APL, XIV 1975, pág. 134. 

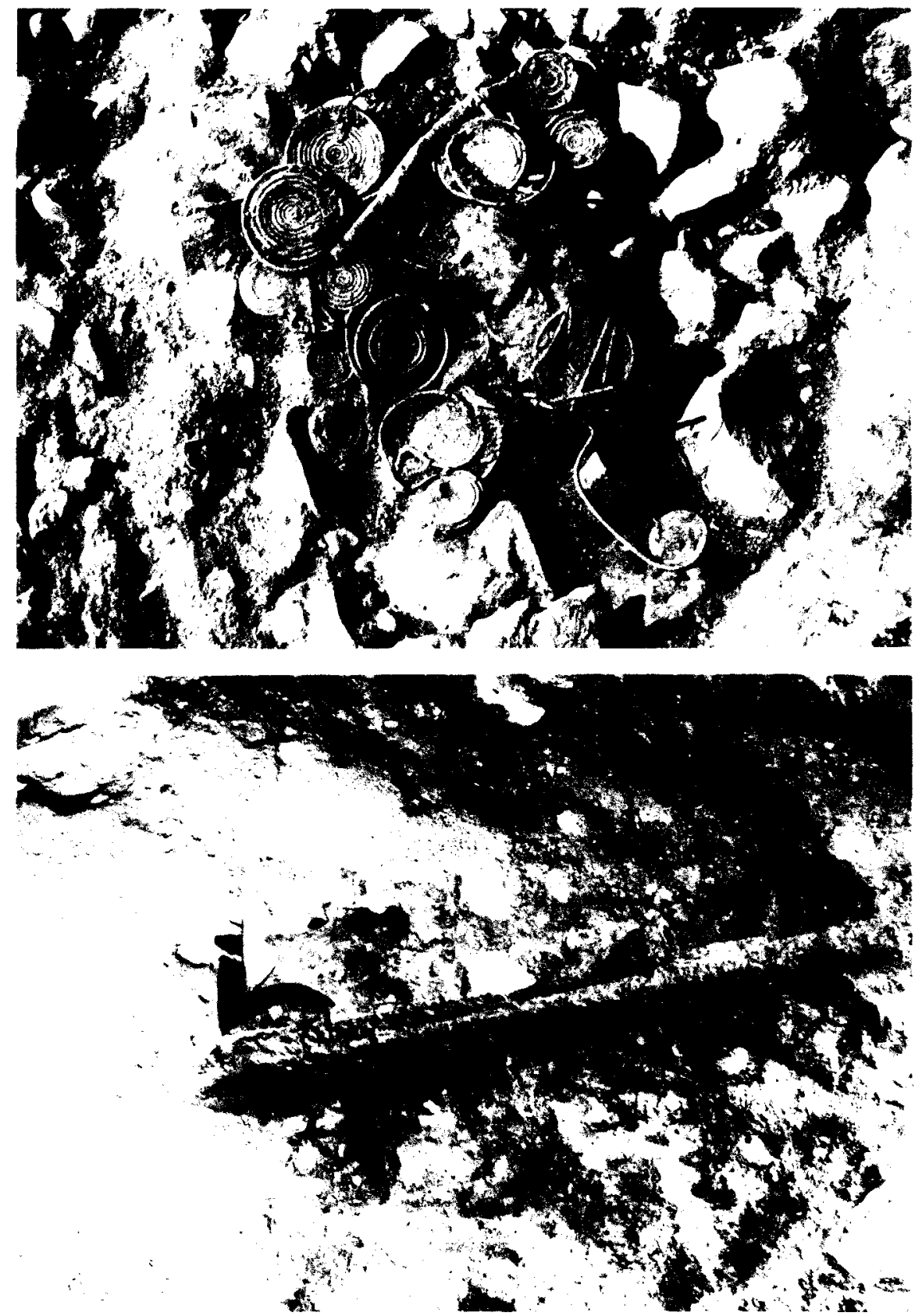

Lamina 1. Proceso de excavacion de dos aluares correspondientes al periodo "pro toceltibérico" (tumbas 305 y 319); el superior corresponde a un individuo civil y el inferior a un guerrero (Fotografias: José Luis Argente). 
Periodos protoceltibérico y celtibérico en la necrópolis de Carratiermes...
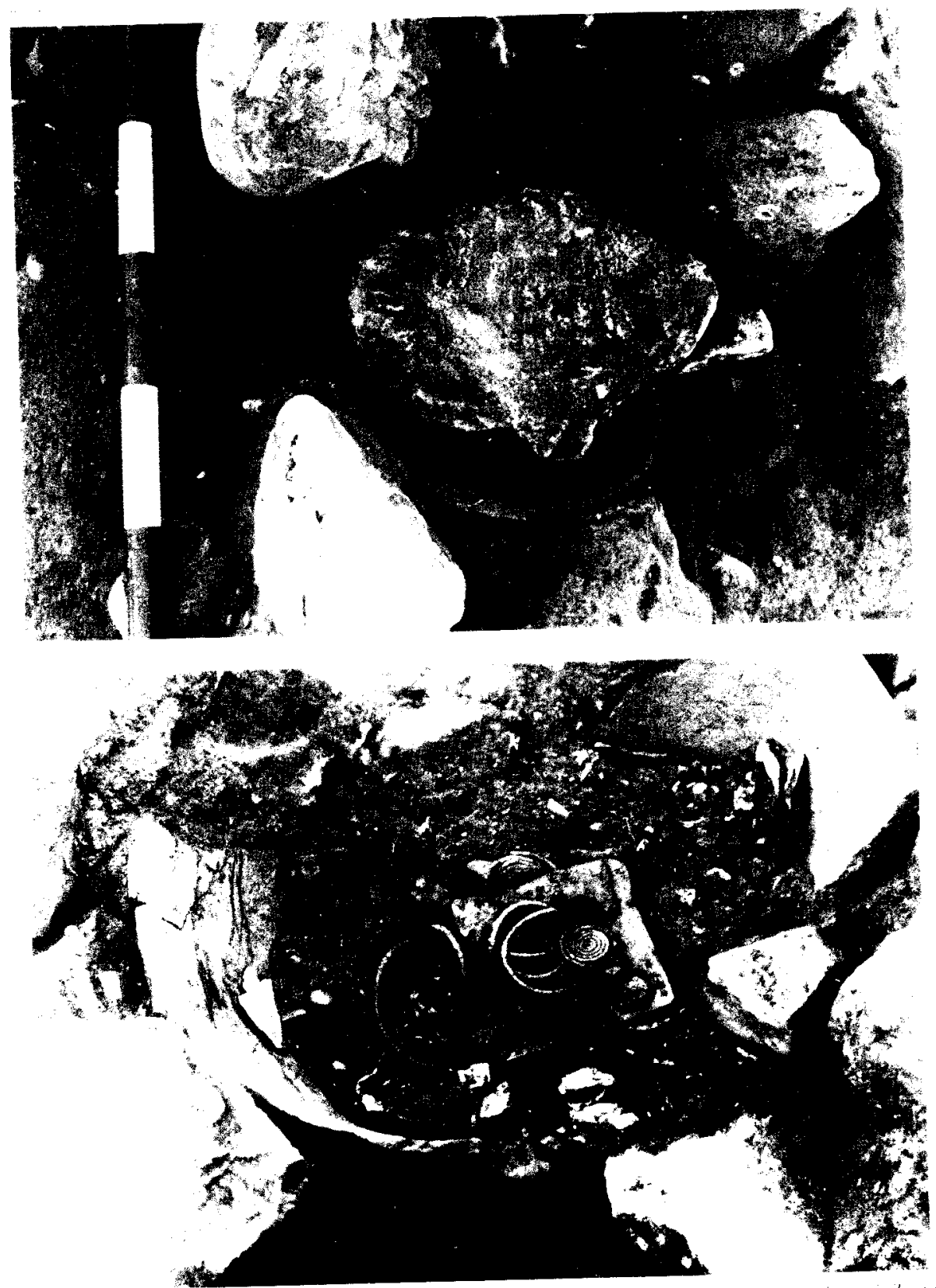

Lamina 1I. Proceso de excavacion de la tumba 92 con ajuar de caracter civil; se halló dentro de una urna realizada a mano y rodeada de estructura pétrea. La boca de la vasija estaba sellada con dos lajas, de las que se ve la inferior (Fotografias: José Luis Argente). 
antiguas, correspondientes principalmente a la Colección Cerralbo ${ }^{7}$. Los modelos que se pueden diferenciar son fundamentalmente dos: los formados por placas metálicas (rectangulares y circulares) y los constituidos por elementos espiraliformes ${ }^{8}$.

En la distribución topográfica de las tumbas que ofrece la necrópolis de Carratiermes, en el estado actual de la excavación, los ajuares que registran en su inventario pectorales de bronce ocupan una zona concreta, en lo que parece ser el centro (o parte más interna) del cementerio; no obstante, estimamos que pueden hallarse más conjuntos que contengan dicho tipo de pieza,s pues todavia no se ha excavado por completo el área que suponemos es el foco de los enterramientos con pectorales.

La mayor parte de las tumbas de Carratiermes con pectorales de bronce, en total 21, se ubican en una misma demarcación de la necrópolis, que, en principio, queda aislada del resto del cementerio, según los últimos datos de la excavación. Se ubican en un área en la que se excavaron 47 tumbas, de las que 21 registran en su ajuar pectorales 0 fragmentos de pectorales de bronce, lo que supone algo más del $36 \%$; el resto de los mobiliarios contienen piezas de guerrero. Lo expuesto significa una fuerte presencia de individuos del estamento civil frente a miembros de la milicia, que, en principio, contrasta con la idea tradicional de que en la sociedad celtibérica (protoceltiberica para el caso que ahora tratamos) predominaba la casta o grupo social guerrero, según la idea que se habia utilizado desde siempre y que permanecía en nuestra bibliografia ${ }^{9}$.

Lo que acabamos de exponer creemos que es una importante y novedosa caracteristica, no advertida hasta ahora en los escasos ajuares conocidos, asi como por desconocimiento también de los conjuntos hallados en las necrópolis ya excavadas; por otro lado, señala las deficientes bases sobre las que se ha apoyado la investigación para el conocimiento de la sociedad a la que pertenecieron los ajuares que presentamos, que

Aguilera y Gamboa Las necrópolis..., obra citada, 1916; Shule, W., Die Meseta kulturen der iberischen halbinsel. Berlin 1969.

"Los ejempiares mejor conservados, tanto pectorales de placa como espiraliformes, además de en Carratiermes, se hallaron en las necropolis de Aguilar de Anguita (Guadalajara) y Alpanseque (Soria) - ver nota 4-y, más recientemente, en la de Ucero, alguna de cuyas piezas se exponen en las Salas del Museo Numantino.

"Perez Casas. J. A., "Las necrópolis", Celtiberos, Catálogo de la Exposición ce!ebrada en Zaragoza en marzo-abril de 1988, pag. 73-80. 
ocupó un área geográfica concreta, a ambos lados de la actual demarcación administrativa de las provincias de Guadalajara y Soria ${ }^{10}$.

Aún podemos aportar otro dato que estimamos relevante: en el estado actual de la investigación de Carratiermes, las lumbas con pectorales de bronce representan el $4,84 \%$ del total de las excavadas; ello, unido a su datación concreta desde fines del siglo $v i$ y durante el $v$ a.C., le incrementan un valor todavía mayor, e indica además la situación dual - militar y civil--, según los ajuares identificados, que quedó establecida en la sociedad protoceltibérica, y que consideramos debió continuar en el tiempo, llegando muy posiblemente hasta bien entrado el siglo ilt y comienzos del II a.C., fechas en la que la situación bélica se hace más significativa e incrementaria el estamento militar (por lo menos se puede deducir esta situación a través de las noticias que nos proporcionan los escritores clásicos, pero ignorando la etapa anterior para la que no se cuenta con ningun otro tipo de información que no sea la que facilitan nan los ajuares en las necrópolis). Estimamos, pues, que la situación descrita no conllevó la desaparición - pero si probablemente la disminución- del sector civil, aunque de momento no se ha podido detectar en los restos arqueológicos, probablemente por no haber identificado la forma material que exprese dicha situación social (que bien pudiera continuar la etapa protoceltibérica o, por el contrario, crear otra de nuevo cuño).

Los conjuntos en donde se inventarian los pectorales de bronce deben ser considerados pertenecientes a individuos de alta posición social. ya que las piezas que constituyen los ajuares denotan una preeminencia económica. La ubicación de estos enterramientos en un area concreta con otros cuyo mobiliario tienen un marcado carácter guerrero, responden tanto a unas mismas condiciones técnicas, como económicas y de categoria social, en cuanto a que se refiere a objetos de prestigio y de coste económico elevado, lo que permite que se pueda y deba considerar como "ricos" a los ajuares de bronce que ahora nos ocupan.

El resto de objetos que se inventaría es muy homogéneo en casi todas las tumbas, existiendo en algunas de ellas un mayor número de piezas que en otras. De los 21 ajuares que conocemos con estas características, se puede señalar que, junto a los pectorales, elemento común a todos ellos, los objetos del mobiliario funerario lo componen, de mayor a menor cantidad registrada, los siguientes: pulseras (12), fibulas (11),

\footnotetext{
10 Argente Oliver, Diaz Diaz, y Bescos Corral, "Placas decoradas...", obra citada.
} 
broches de cinturón y cuchillos de hoja curva (7) y collares de cuentas de pasta vitrea o piezas sueltas (6). Lo indicado puede considerarse como "ajuar tipo", que representaria el mobiliario que nosotros atribuimos a un "individuo rico no guerrero"; dentro de esta combinación de ełementos de ajuar, un único objeto de hierro que suele acompañarle es el cuchillo de hoja curva, que estimamos de uso múltiple y, aún cuando puede ser utilizado como arma, nos inclinamos a pensar más bien en su empleo como objeto de la vida cotidiana ". En este sentido, ha de señalarse que los cuchillos de hoja curva inventariados hasta la fecha en Carratiermes se aproximan a las 150 unidades (registrados en tumba o fuera de ellas), cantidad que induciria a atribuirle la función expresada anteriormente.

Asi, pues, conocemos el ajuar tipo de un individuo no guerrero diferenciado socialmente (ya que entendemos que los objetos hallados corresponden a uso personal y de distinción entre los demás individuos de un núcleo de población), lo que permite establecer la línea de investigación que ayude a adentrarnos en el conocimiento de la sociedad protoceltiberica y celtibérica; además la diferencia entre unos y otros ajuares estriba en el tipo de pectoral identificado, en el modelo de fibula $y$, en menor grado, en las cuentas de collar registradas, pues los broches de cinturón y cuchillos de hoja curva responden en todos los casos a un mismo modelo. Todos los detalles apuntados permitirán, en futuros estudios, ir concretando el esquema de la sociedad celtibérica de la Meseta Oriental a través del ajuar funerario, puesto que, por el momento, no disponemos de otro elemento de información que complemente los hallazgos materiales que se van produciendo en las excavaciones arqueológicas que se realizan en la actualidad.

- Ajuares de guerrero. Ya hemos mencionado que las tumbas con piezas de bronce se disponen junto a otras que, gozando de la misma datación cronológica, tienen un sentido diferente y corresponden, a juzgar por los objetos inventariados, a iridividuos del estamento militar; no obstante, los objetos recuperados señalan ciertas diferencias con los ajuares de la élite militar de fechas posteriores.

El mobiliario del guerrero protoceltibérico se caracteriza por presentar, como norma general y de acuerdo con los datos que poseemos hasta el presente en la necrópolis de Carratiermes, las siguientes piezas: puntas de lanza de tamaño grande - suelen sobrepasar los 50 y $60 \mathrm{~cm}$ de

Alonso LuBIAS, "Broches de cinturón...", obra citada. 
longitud-, y con marcada nervadura central; regatones, cuyo tamaño se hallan en relación al de las puntas de lanza; en ciertos casos, arreo de caballo; cuchillo de hoja curva; fibula de bronce o hierro - en este material serán menos frecuentes en etapas posteriores-; broches de cinturón, mayoritariamente de tres garfios y escotaduras cerradas, del tipo D III.3 de Cerdeño ${ }^{12}$, aunque también los hay de un sólo garfio y escotaduras cerradas. Las espadas y puñales conocidos en Carratiermes corresponden a las siguientes centurias.

Algunos conjuntos presentan piezas poco frecuentes, como es el caso de calderos de bronce, que aparecen aplastados con clara intencionalidad, y que se registran -hasta el presente - en dos tumbas - números 321 y 327-, o un cazo de bronce - tumba número 362-; la presencia de estos objetos permite pensar, si el tanto por ciento se mantiene, en una importación de piezas de origen más lejano que las frecuentemente registradas en los ajuares ya excavados. Otro caso poco usual es el hallazgo de una lima de hierro, como el inventariado en la tumba número 337; este objeto debió de ser empleado en alguna actividad concreta, caso del trabajo del hueso.

Así, pues, queda reflejado perfectamente en lo expuesto la diferencia entre los dos tipos de ajuar que se desarrollan en la etapa protoceltibérica, y que responden a los dos estamentos sociales ya indicados.

\section{DISTRIBUCIÓN TOPOGRÁFICA DE ESTOS AJUARES EN LA NECRÓPOLIS DE CARRATIERMES}

Aún cuando no se ha excavado la totalidad de este cementerio, ni siquiera el área que suponemos restringida para estos ajuares, se puede pensar con la información actual que, tanto las tumbas con mobiliario de piezas de bronce como las de guerrero de la fase protoceltibérica, ocupan unos límites superficiales concretos, en los que parece constituir el interior del área a partir de la cual se extiende la ocupación de la necrópolis, ya que se documentan en su entorno los enterramientos de cronología posterior. De momento, no estamos todavía en posición de afirmar

12 Cerdeño Serrano, M. L., "Los broches de cinturón peninsulares de origen céltico", TP, 35 (1978), págs. 279-306. 

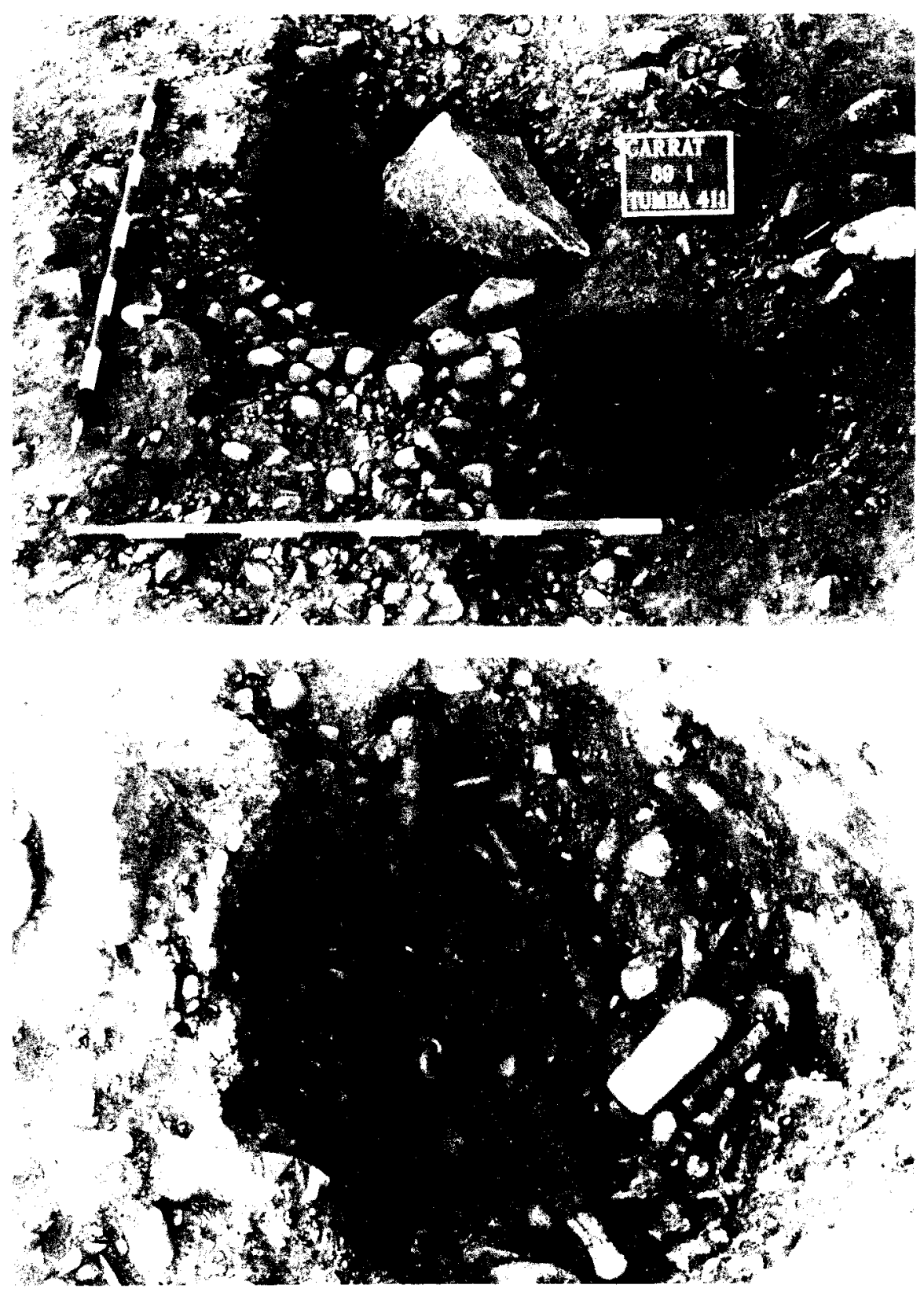

Lamina III. Afuar de guerrero del periodo celtiberico pleno, colocado en un hoyo excavado en el conglomerado natural; junto al ajuar, se realizó otra perforación en el suelo del lugar para situar la estela de piedra, de la que sólo se halló su base. La fotografia inferior recoge un detalle del ajuar (Fotografias: José Luis Argente). 
si la expansión de la necrópolis se hizo a partir de un punto y en estratigrafía horizontal, o bien el incremento de ocupación del suelo para enterramientos se hizo en áreas, siempre desde la zona que ocupan las tumbas más antiguas, aunque desarrolladas en un mismo plano horizontal, sin superposición de estructuras funerarias.

En futuras campañas esperamos obtener los datos que nos permitan resolver este aspecto y que ayuden a asegurar uno u otro planteamiento, pudiendo conocer desde entonces mejor la distribución de las tumbas y estructuras en una necrópolis celtibérica, aunque es lógico pensar que, aún dentro de una normativa general, pueden existir diferencias entre los diversos cementerios que se establecieran en el área de nuestro estudio.

\section{CRonología de los ajuARES de bRonce y de GUERRERo}

Una vez expuestas las peculiaridades de estos ajuares, su composición, ubicación y dispersión en el área excavada en la necrópolis de Carratiermes, vamos a analizar los distintos elementos que componen los ajuares "ricos" de bronce, con el fin de establecer su cronología, aspecto que también servirá para el conjunto de tumbas cuyo mobiliario funerario constituye el ajuar de guerrero.

Para ello nos apoyaremos en los estudios de dos tipos de piezas: los broches de cinturón ${ }^{13}$ y las fíbulas ${ }^{14}$, puesto que se trata de dos elementos que forman parte, por regla general, del ajuar de bronce tipo, asociandose también a los mobiliarios de guerrero, y que han sido objeto de estudios recientes en profundidad, permitiendo fijar dataciones seguras.

Respecto a los primeros, el número con que contamos es de 8 ejemplares distribuidos en 7 tumbas $(2$ hembras, 4 machos y una pieza compuesta de macho y hembra); todos ellos corresponden ${ }^{15}$ al tipo D III.3 de Cerdeño ${ }^{16}$, quien fecha el mismo entre muy fines del siglo vi y fines del $\checkmark$ a.C., datación que se asemeja con la que proporcionan la fíbulas aso-

\footnotetext{
3 Passim.

14 Argente Oliver, J. L. Las fibulas en la Meseta. Su valoración tipológica, cultural y cronológica. Universidad Complutense, Madrid, Tesis Doctoral, número 54/89, pág. 1034

is ALONSO LUBIAS, "Broches de cinturón...", obra citada.

16 Cerdeño Serrano, "Los broches...", obra citada, págs. 295-296
} 
ciadas o para las tumbas del sector de la necrópolis de Carratiermes del que ahora nos ocupamos. Los datos seguros que aporta Cerdeño le permiten exponer la datación que ofrece, y que nosotros ratificamos con los hallazgos de Carratiermes; sin embargo, los ejemplos que cita se encuentran muy dispersos geográficamente, y curiosamente ninguno en la zona en que se ubica nuestra necrópolis, cuando, según su inventario, son abundantes en la misma, pero procedentes de yacimientos en donde no se pueden asociar los broches de cinturón a conjuntos cerrados ${ }^{17}$. Carratiermes ofrece, dentro del área oriental de la Celtiberia, la posibilidad de dataciones seguras, con ajuares concretos y estuctruras funerarias completas, tal como ha señalado Alonso en un estudio - hoy en prensa- sobre estas piezas termestinas ${ }^{18}$.

En cuanto a las fibulas, el inventario que hay en las 21 tumbas que tratamos para el estudio de los pectorales ofrece una variedad importante de modelos y tipos, pero todos dentro de un periodo cronológico similar. El total de fibulas es de 20, repartidas en 10 tumbas, de las que dos tienen 4 piezas, una contiene 3 , en dos hay 2 ejemplares y en cinco tumbas una fíbula en cada una. Todas ellas se clasifican en los siguientes modelos: sin resorte 3 ejemplares (siglo VI a.C.) ${ }^{19}$; de doble resorte otros 3 (fines VI-fines $\vee$ a.C.); de anular hispánica 2 ( $\vee$ a.C. al I d.C.); de pie vuelto 7 (mediados $v 1$-fin $\vee$ a.C.); de espirales 4 (fines vi-comienzos IV a.C.); y sin definir 1 sola pieza.

Como se puede apreciar, los modelos y tipos de fibulas que se registran en las tumbas en las que hay pectorales de bronce, se fechan entre fines del siglo $v i$ y todo el $v$ a.C., a excepción de uno el $-6 b-$ cuya perduración se prolonga hasta el siglo 1 d.C. ${ }^{20}$, pero en el ajuar a que pertenece debe fecharse en el siglo $v$ a.C., pues el conjunto total corresponde a esa centuria. El resto de las piezas que se inventarian en los mobiliarios estudiados no presentan dataciones concretas, por lo que deben quedar dentro de la fecha del conjunto. También hay que indicar que en las tumbas de guerreros, ubicadas junto a las de ajuar de bronce, y en cuyos inventarios existen broches de cinturón y fíbulas, de los mis-

Cerdeño Serrano, obra citada, págs. 296 y 285.

18 LUBIAS, Alonso; Broches de cinturón...", obra citada.

19 Maluquer de Motes, J., "El castro de Los Castillejos en Sachorreja", Salamanca 1958, pág. 96. Sólo en este yacimiento se han podido fechar varios ejemplares; el otro conocido procede de la necrópolis de Valdenovillos (Guadalajara): ver ARGENTE OLIVER, "Las fibulas...”, obra citada, 1989, pág. 266. Ahora en Carratiermes se conocen ya varios ejemplares más de este tipo de fibula, hallados en ajuares completos.

* ARgente Oliver, "Las fibulas...", obra citada, 1989, págs. 264-279. 
mos modelos y tipos que los señalados para aquéllos, ofrecen la misma datación.

En consecuencia, se puede deducir que los ajuares «ricos" de bronce (correspondientes a individuos del estamento civil) y los de guerrero, dentro de la misma zona (presumiblemente la más interna del área cementerial de Carratiermes), con objetos coincidentes en cuanto al uso y modelo -broches de cinturón, fibulas y cuchillos de hoja curva- corresponden a una misma etapa cronológica (fines de siglo vi y todo el $v$ a.C.) y cultural (la protoceltibérica).

\section{SIGNIFICACIÓN SOCIAL DE ESTOS CONJUNTOS}

De todo lo anteriormente expuesto, se puede deducir que los pectorales conforman un ajuar que señala la posición social elevada de la persona que utilizó dichas piezas, y que se pueden oponer a los contemporáneos con armas $y$, por lo tanto, no tienen la significación de potenciación de la figura del guerrero. Ante esto sólo tenemos dos opciones: o aceptar la opinión tradicional de que dichas piezas pertenecian y representarian a mujeres de categoria social destacada - por ejemplo, las sacerdotisas del sol según el Marqués de Cerralbo- ${ }^{21}$, o, por el contrario, se pueden buscar otras explicaciones en el plano social, pues pudiera estar en relación con el consejo de ancianos documentado por las fuentes, y ser por tanto enseñas o emblemas que les distinguian con referencia a otros individuos de su misma tribu o ciudad. Sin embargo, aún se podrían considerar posiblemente otras posturas $-y$ esto lo queremos remarcar - para poder tener otros modelos complejos de la sociedad celtibérica. No obstante, la presencia del número ya importante de ajuar con pectorales $-36 \%$ en su zona - que, a partir del siglo $v$ a.C. se reduce de manera drástica, incrementándo, por otra parte, el número de piezas que componen el del guerrero, donde se relacionan ya espadas entre sus elementos de ajuar, nos permite sospechar, todavía sin datos que nos los confirmen, que se trata de piezas pertenecientes a varón. Los análisis óseos, entre otros estudios, posibilitarán contar con elementos de juicio suficiente que apoyen o nó lo que de momento proponemos. Si ello

\footnotetext{
21 Aguilera y Gamboa, "Las necrópolis...", obra citada, 1916, págs. 61-72.
} 
es asi, las necrópolis que conocemos hasta el presente resultarian ser mayoritariamente masculinas.

Si entendemos que los objetos que se registran en los ajuares excavados son bienes de prestigio, por lo tanto no al alcance de todos los individuos; si también admitimos que la sociedad protoceltibérica y celtibérica estaba estratificada y que sólo una minima parte de los habitantes podía acceder a esos bienes de prestigio importantes y ostentar asi el poder económico y social; y si, de igual manera, no olvidamos las infomaciones que las fuentes señalan, referidas ya a un periodo cronológico posterior al que ahora tratamos ( $y$, tal vez, algo diferente para la fase protoceltibérica), en relación a un exceso de población, por lo que parte de la misma emigra (sobre todo formando parte de las tropas cataginesas y romanas), podriamos plantear las siguientes hipótesis de cara al futuro de esta investigación:

1. Las áreas comentariales celtibéricas conocidas se destinan a personajes masculinos importantes de la sociedad y a sus fideles, quienes, en torno a su señor, con ninguno o escasísimos elementos de ajuar, elevan la significación del enterramiento principal.

2. Habrá que suponer que, si estas necrópolis responden sólo a una parte de la sociedad, existirán otros lugares para el resto de la población o, por contra, que el rito funerario celtibérico reservara para ellos otra modalidad que se desconoce actualmente.

Si lo que acabamos de apuntar como reflexión es el camino correcto, podriamos resumir que en la etapa protoceltibérica, sobre la base de los enterramientos excavados, el número de individuos de carácter civil es importante frente al de los guerreros, siendo además dudosa la adscripción de dichos ajuares a mujeres, por lo que habria en estas necrópolis mayoria o totalidad de varones enterrados.

\section{ESTRUCTURAS Y AJUARES DEL PERIOODO CELTIBÉRICO PLENO}

En el área excavada, en torno a las estructuras funerarias protoceltibéricas, se identifican otras que, aún manteniendo caracteristicas morfológicas similares, evidencian ya un cambio cronológico, que queda reflejado en las piezas inventariadas, aunque, por otro lado, se mantienen, en algunos casos con ligeras diferencias, otros aspectos del ritual 
Periodos protoceltibérico y celtibérico en la necrópolis de Carratiermes...
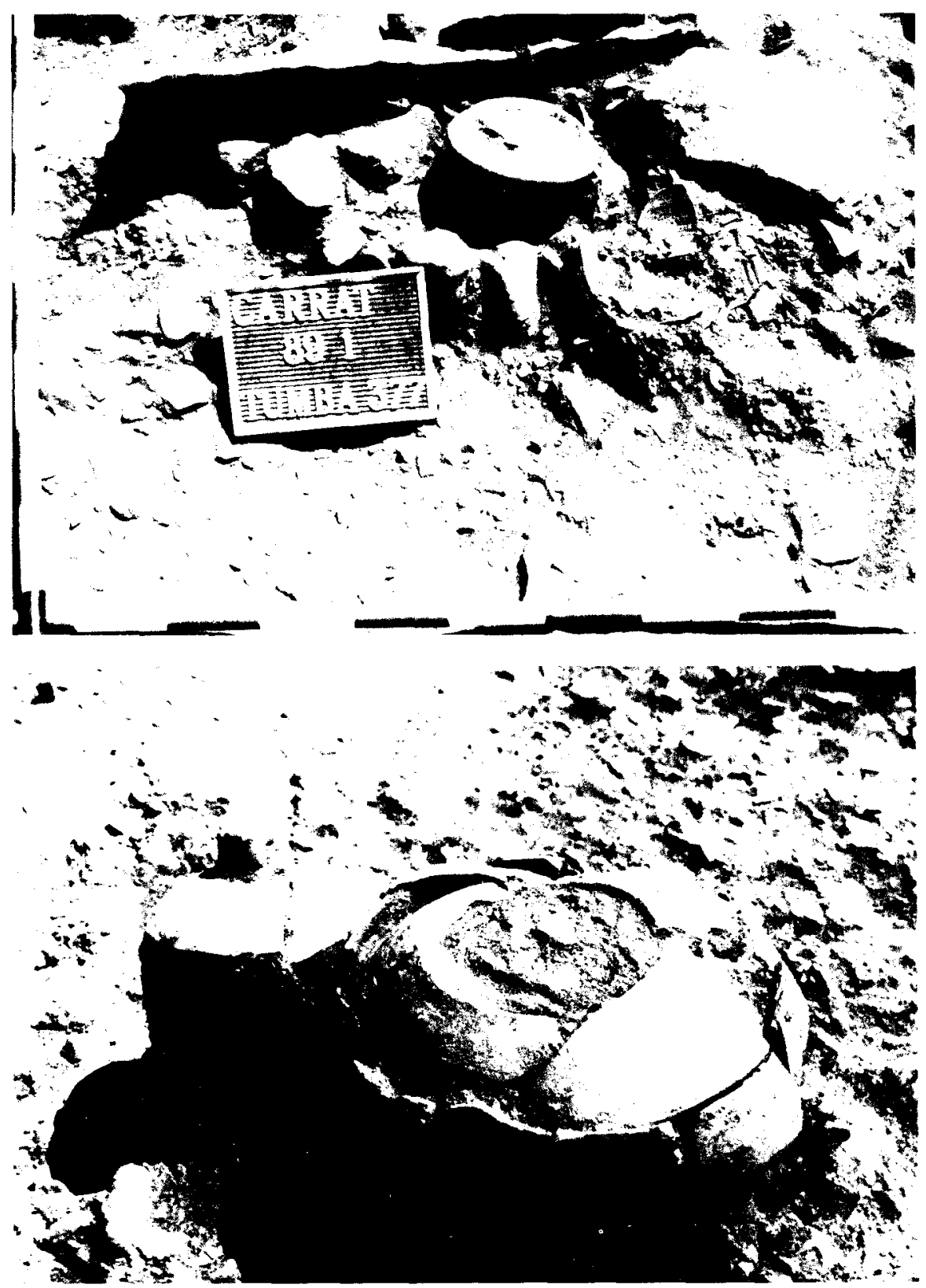

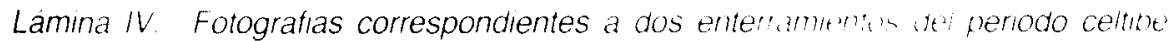
rico pleno en la superior, la estructura pétrea presenta und laja de piedra en el lado oriental de la tumba, con orientación norte-sur. La urna se sujetaba con varias piedras, entre las que quedaba el ajuar metálico (Fotografias. José Luis Argente). 
funerario. Así, perduran los hoyos excavados en el conglomerado natural, y comienzan a senalarse otros tipos de estructuras pétreas que protegen el mobiliario funerario; se trata de unas lajas de caliza orientadas de norte a sur, en cuyo flanco oriental se deposita la urna y/o el ajuar que queda protegido por las piedras que completan el cubrimiento del enterramiento. Sin embargo, hay casos en los que el ajuar solamente lo constituye la urna, con o sin cubierta pétrea.

En el periodo celtibérico pleno se incrementa el número de vasijas funerarias que, en su mayor parte, son ya piezas oxidantes y realizadas a torno; el número de elementos metálicos se mantiene, pero, en el caso de Carratiermes y en el estado actual de conocimiento, se puede señalar que disminuyen de manera radical los broches de cinturón y los pectorales de bronce; por el contrario, aquél que consideramos ajuar de guerrero queda tipificado dentro de las caracteristicas que se conocian hasta el presente. Si conviene señalar que ciertas piezas, puntas de lanza y regatones por ejemplo, reducen de manera importante su tamaño.

- Ajuar de guerrero. Al igual que para el período anterior, conocemos las características tipo del ajuar de guerrero del período celtibérico pleno; se compone generalmente de espada de antenas, puñal tipo Monte Bernorio o puñal biglobular, puntas de lanza, regatones, cuchillos de hoja curva, bocados y arreos de caballo, etc. No en todos los casos, pero si en un tanto por cien elevado, suele acompañar a estas piezas, fibulas $u$ otros objetos de adorno, caso de las denominadas "pinzas de depilar". En casos muy concretos se inventarian elementos que no son tan frecuentes, como son los umbos de escudos - registrados en las tumbas números $399,407,411$ y otras-, soliferreum -en el ajuar número 407-o piedra de afilar - en la tumba número 411 - , pieza raramente catalogada en este tipo de estaciones y que seria un objeto bastante común para mantener el filo de las armas ${ }^{22}$.

Los elementos protagonistas de estos conjuntos son las espadas y puñales, que ahora definen al estamento guerrero durante los siglos IV al II a.C., y de los que se anotan un nutrido grupo de ejemplares en Carratiermes, $y$, en general, en todas las necrópolis del período cronológico a que hacemos referencia.

Los tipos inventariados en la presente campaña son:

${ }^{22}$ Necrópolis de Ucero, información facilitada por el Director de dicha excavacion, D. Ernesto Garcia-Soto Mateos, a quien damos las gracias por las noticias facilitadas. 
- Espadas de antenas atrofiadas. Dentro de las espadas cuyo pomo remata en esferas, hay varios tipos, entre ellas el de antenas atrofiadas propiamente dichas, de hoja corta con $40 \mathrm{~cm}$ de longitud media, y acanaladuras en la hoja en sentido Iongitudinal. En Carratiermes hay siete ejemplares del tipo descrito, contextualizados en tumba, además de otros recogidos en niveles de revuelto.

- Puñales biglobulares. Se trata del puñal corto típico del mundo celtibérico, que perdura hasta la etapa romana. La empuñadura, que le confiere su nombre, es muy característica, presentando en ella dos pequeños círculos o globos en su parte media y superior. En general, la longitud del puñal completo oscila sobre los $25 \mathrm{~cm}$. Es el tipo más abundante en la necrópolis de Carratiermes, ya que por el momento han aparecido siete ejemplares en tumbas y otros fuera de ellas.

No obstante, debemos señalar que en el yacimiento, aunque correspondientes a otras campañas, se han inventariado otros modelos de espadas y puñales, como son las de antenas tipo Echauri y Alpanseque, y el puñal de tipo Monte Bernorio, pieza no muy frecuente en las necrópolis de la Meseta Oriental ${ }^{23}$. Finalmente, hemos de citar la espada de La Tène, que, aunque no hallada todavía en ninguno de los ajuares excavados, puede mencionarse también en Carratiermes, si la pieza publicada por Ruiz Zapatero y Núñez Garcia procede efectivamente de la necrópolis termestina ${ }^{24}$.

- Ajuar sin armas. Junto a las anteriores, existe un grupo importante de tumbas que solamente presentan como ajuar la urna funeraria (dentro de la cual quedan los restos óseos del difunto), y a lo sumo acompañada por otras piezas cerámicas - bolas, fusayolas, etc.--; en casos excepcic vales, se registra alguna pieza metálica de adorno -fibulas, pendientes, etc.-.

Estos ajuares suelen hallarse dentro de estructuras pétreas, aunque, en otras ocasiones, se encuentran las urnas cerámicas depositadas directamente en el suelo. Todavía no tenemos datos suficientes para señalar a qué puede corresponder cada uno de estos casos; sin embargo, si estamos en condiciones de afirmar la cronología para buena parte de ellas, ya que la presencia de piezas, como las fíbulas, permite una datación que ayuda en la fijación temporal de los ajuares.

\footnotetext{
23 Sanz Minguez, C., "Variantes del puñal de tipo Monte Bernorio en el Valle Medio dei Duero", BSAA, Lll (1988), págs, 25-46.

24 Ruiz Zapatero, y Nuñez Garcia. “Un presunto ajuar...”, 1981, págs. 189-194.
} 


\section{CONSIDERACIONES GENERALES DE LOS RESULTADOS DE LA CAMPAÑA DE VERANO DE 1989 EN RELACIÓN AL CONJUNTO TOTAL DE LA NECRÓPOLIS}

Tal vez la aportación más señalada de la campaña de 1989 sea la detección y presencia de conjuntos de estructuras y ajuares pertenecientes a la fase que denominamos "etapa protoceltibérica". Por esta razón, nos hemos extendido más en ella, procurando explicar y aportar datos e hipótesis de trabajo que estamos manejando en estos momentos, con el fin de poder comprender un momento bastante desconocido, del que se tenía cierta información pero que no aportaba conclusiones claras; nos parece encontrarnos en una linea de investigación prometedora y que, avanzados los trabajos, podremos expresar más detenidamente su desarrollo.

Expuestos los datos precedentes $y$, teniendo en cuenta el estado actual de nuestra investigación, podemos reseñar, con el carácter de provisionalidad que ello conlleva, las siguientes conclusiones para cada uno de los dos periodos que distinguimos:

\section{Fase protoceltibérica}

Hay que destacar, en el período protoceltibérico, la presencia de unas piezas que denominamos "pectorales", en los que distinguimos dos tipos: los fabricados con placa —circulares y rectangulares-y los espiraliformes - constituidos a base de espirales - ${ }^{25}$.

Los ejemplares que se distinguen actualmente son muy escasos, sobre todo piezas completas o que conservan parte de las mismas; el

Cabre de Moran. y Moran Cabre. "Dos tumbas datables...", obra citada, 1975, pág. 134. Ya hemos comentado anteriormente que estos autores expresan una opinión diferente a la indicada por Cerralbo y Cabré en cuanto a la adscripción de uso de este tipo de objetos y dicen" ... creyeron que esta bellísima pieza --se refieren a un pectoral espiraliforme- se habia empleado a modo de diadema, pero nosotros, observando su inusitado tamaño, y teniendo en cuenta que sólo las espirales de mayor tamaño sostienen los colgantes de campanillitas [aspecto que nosotros no admitimos, ya que esos adornos corresponden, como hemos podido comprobar en diversas piezas completas en Carratiermes, a los pectorales de placa y nunca a los espiraliformes| nos inclinamos a pensar que este objeto, convenientemente curvado su vástago central, pudo usarse como pectoral ...". 
resto de las que se pueden reconocer en los materiales de necrópolis antiguas (sobre todo en los fondos de la Colección Cerralbo), se centran en espirales sueltas y en fragmentos de vástago de los que nacen aquéllas. Lo mismo sucede con aquellos objetos que se componen de placa rectangular y adornos de campanillas (de los que también se conocen parte de piezas completas), siendo, como en el caso anterior, las de Carratiermes las que ofrecen la unidad básica para el conocimiento de estos pectorales. En resumen, podemos decir que este tipo de objetos es minoritario en la necrópolis de Carratiermes, pero su número se reduce mucho más en todos los demás yacimientos juntos.

El resto de las piezas que acompañan a los pectorales, dentro del ajuar que calificamos como correspondiente a un individuo del estamento civil, denotan una datación antigua, caso de las fibulas ${ }^{26}$ y broches de cinturón ${ }^{27}$; por ello, se puede señalar que los objetos de los ajuares descritos responden a ese primer momento de formación del mundo celtibérico en la Meseta Oriental.

Los ajuares de guerrero gozan también de unas peculiaridades que permiten diferenciarlos de otros de época posterior; hay que señalar, entre otras características, las puntas de lanza y regatones, acompañados bocados de caballo y, sobre todo, fíbulas y broches de cinturón, de los mismos modelos y tipos que los registrados en los ajuares del estamento civil.

En resúmen, podemos señalar las siguientes notas que definen, siempre en el estado actual de investigación de la necrópolis de Carratiermes, los conjuntos que atribuimos a la fase protoceltibérica:

- Las tumbas donde aparecen los pectorales ocupan un lugar determinado en el área de la necrópolis, suponiendo que puedan cubrir la zona interna del cementerio a partir de la cual se expanden, bien constituyendo círculos o bien sectores concretos con datación algo más moderna; de esta manera se fue ampliando el área de enterramiento, hasta llegar a cubrir la superficie que hoy creemos puede ocupar la necrópolis celtibérica de Carratiermes.

- En ese foco de establecimiento de tumbas protoceltibéricas existe una dualidad básica de los ajuares: los correspondientes al estamento civil y los pertenecientes al militar.

\footnotetext{
26 ARgente OLIVER, «Las fibulas..." 1989.

${ }^{27}$ Cerdeño SerRano, "Los broches...", 1978.
} 
- Los ajuares descritos señalan y reconocen una posición social y económica determinada, y que las piezas enterradas representan bienes de prestigio entre la población, además de su utilidad concreta, como es el caso de las armas, tanto para defensa como para ataque.

- Se reconoce la potenciación del ajuar sin armas, aspecto que no se habia detectado en las investigaciones realizadas para esta sociedad; asi, se fortalece y pone en relevancia la importancia civil del individuo y de un sector social de carácter no bélico.

- Por los objetos que componen el conjunto de piezas de bronce establecemos la datación desde la segunda mitad-fines del siglo vi y durante todo el $\vee$ a.C., etapa anterior a la de cristalización de la cultura celtibérica.

\section{Fase celtibérica plena}

Al igual que en el caso anterior, se pueden diferenciar ciertos aspectos que permiten extraer diversas características para identificar plenamente esta fase; la mayoría de aquéllas ya fueron establecidas por autores precedentes, significando nosotros solamente ahora las más relevantes, y en base a los hallazgos de Carratiermes:

- Presencia de espadas de antenas - en los diversos tipos de las mismas - y de puñales, al final del periodo cronológico de esta fase, que señalan un cambio en cuanto al ajuar militar de los individuos de la sociedad celtibérica. Se mantienen otros objetos ya inventariados anteriormente, como puntas de lanza, regatones, bocados de caballo, cuchillos de hoja curva, etc.. Las piezas de adorno, casi exclusivamente fibulas y pinzas de depilar, corresponden a la fecha en la que encuadramos estos hallazgos.

Es de destacar, como ya se ha indicado, la ausencia casi total de broches de cinturón, aspecto que, por el momento, no podemos indicar a qué puede ser debido.

- Respecto a los enterramientos de individuos del estamento civil, no hay indicadores explícitos como en la fase anterior protoceltibérica, que nos indiquen sus caracteristicas; no obstante, se podría decir que ahora son los correspondientes a esta clase social aquellos ajuares que presentan mobiliario compuesto sólo por la urna funeraria y, en algunos casos, objetos de adorno, bien realizados en arcilla o en bronce. 

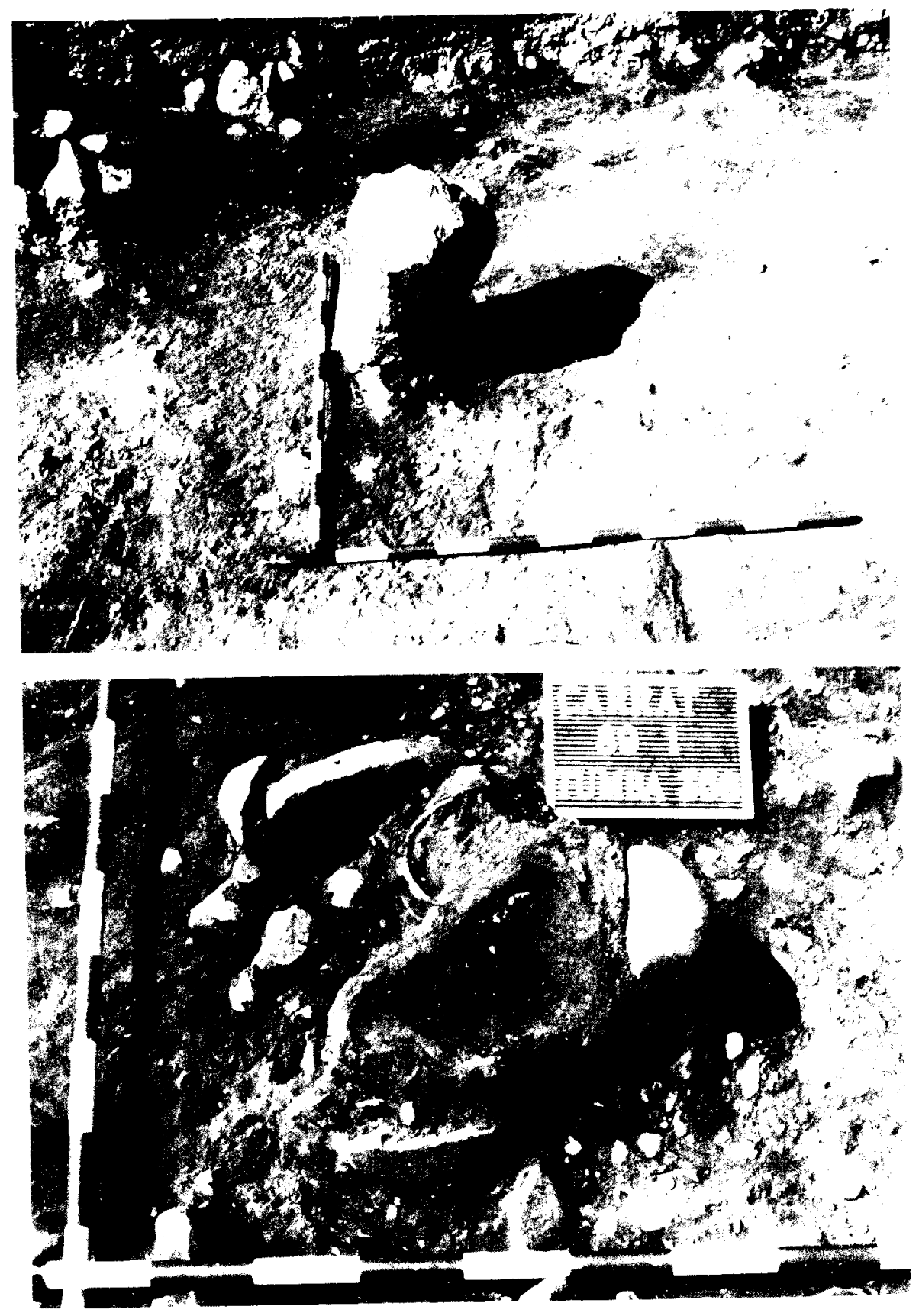

Lámina $V$. Estructura funeraria pétrea del periodo celtibérico pleno, dentro de la cual se depositó la urna funeraria. En la fotografía inferior, se presenta la base de una estela de piedra, que fue rota por la acción del arado (Fotografias: José Luis Argente). 
Así, pues, los datos expuestos para el estudio de las fases que distinguimos, permiten contemplar el mundo celtibérico desde otras perspectivas, a partir de las evidencias materiales que está proporcionando la excavación de Carratiermes, que estimamos interesantes y que podrán, en un futuro no muy lejano, establecer unas pautas para la mejor comprensión de esta sociedad, de la que se cuenta con numerosos yacimientos, piezas significativas y un escaso conocimiento, no sólo de la sociedad celtibérica, sino de sus ritos funerarios, estructuras y composición de sus tumbas y un detallado exámen de los materiales que compusieron los ajuares de las mismas.

Finalmente, y aun cuando no es propósito del presente estudio, diremos que la utilización de la superficie de la necrópolis de Carratiermes, con tal función, continúa posteriormente, llegando hasta el siglo I d.C. y posiblemente hasta el comienzo de la siguiente centuria; para ello, contamos con material romano incluido entre el ajuar depositado en algunas de las tumbas excavadas (fundamentalmente piezas de vasijas de terra sigillata hispánica y monedas, ases con leyendas latinas), lo que permite suponer que las formas y ritos, aun cuando se pueden perder ciertos aspectos, sobre todo en el tipo de ajuar, se mantienen plenamente en vigor después de la conquista romana ${ }^{28}$. Tal vez influya en ello la tardía dominación de Tiermes - sometida en el año 98 a.C.-., lo que le perimitiria conservar en esas fechas aspectos que posiblemente no se mantendrían vigentes en otros lugares próximos, pudiendo pensar que esta zona quedó, en cierto modo, como reducto anquilosado para algunas costumbres indígenas.

28 Argente Oliver, J.L. y Jimeno Martinez, A., "Tres tumbas de incineración de época romana, halladas en Uxama (Osma, Soria)", Celtiberia, 53 (1977), págs 29-40; en estas tumbas, aun cuando el ajuar es ya de época romana, todavía el rito corresponde al tradicional del área. utilizando una piedra en la que se ejecutó un hoyo semiesférico, y en el que se despositaron los restos de las cenizas y el ajuar - dos piezas de vidrio-. Quedo sellado con un cono de piedra, sujeto a la parte inferior con cuairo grapas de hierro y plomo fundido. Estimamos que el cono pétreo pudo ser reminiscencia de la estela que se colocaba en etapas anteriores. 